\title{
New views of hypnotizability
}

\author{
Enrica L. Santarcangelo * \\ *Correspondence: enricals@dfb.unipi.it \\ Edited by: \\ Shigeyoshi Itohara, RIKEN Brain Science Institute, Japan \\ Reviewed by: \\ Masao Ito, RIKEN Brain Science Institute, Japan \\ Akira Katoh, Tokai University, Japan
}

Department of Translational Research and New Technologies in Medicine and Surgery, University of Pisa, Pisa, Italy

Keywords: hypnotizability, imagery, cerebellum, postural control, voluntariness, nitric oxide

\section{INTRODUCTION}

Hypnotizability, or hypnotic susceptibility (Green et al., 2005), is a good predictor of the response to suggestions in and out of hypnosis (Meyer and Lynn, 2011). It can be measured by scales (Sheehan and McConkey, 1982) allowing to classify subjects as high (highs), medium (mediums), and low (lows) hypnotizable by indicating the individual ability to modify experience and behavior according to the suggestions' content and to feel that this occurs independently of will.

In the ordinary state of consciousness, highs and lows can be discriminated by the predictability of their electroencephalographic (EEG) dynamics, while the several studies performed through spectral analysis of EEG failed to indicate clearcut discrimination criteria (Madeo et al., 2013). Imaging studies (Hoeft et al., 2012) have associated high hypnotizability with greater functional connectivity between the left dorsolateral prefrontal cortex, an executive-control region, and the salience network (dorsal anterior cingulate cortex, anterior insula, amygdala, ventral striatum) involved in detection and processing of relevant information (Figure 1). This is consistent with the evidence that highs tend to become deeply absorbed in any task of everyday life (Tellegen and Atkinson, 1974; Kihlstrom et al., 1989); nonetheless, the theory attributing the highs' peculiar ability of focusing attention on selected internal or external objects as the basis of hypnotic responding (Raz, 2005; Szekely et al., 2010) has been challenged by neuropsychological and genetic studies. The former have denied any association between various attentional abilities and hypnotisability (Varga et al.,
2011), have shown only higher arousal in highs (Castellani et al., 2007) and have suggested that the highs' attention is more stable (less distractible) rather than more flexible than the lows' one (Jamieson and Sheehan, 2004; Egner et al., 2005); genetic studies (Presciuttini et al., 2014) have refuted the hypothesis that reduced dopamine catabolism associated with polymorphism of the brain CatecholO-Methil-Transferase (COMT) may be responsible for the highs' attentional abilities, as no difference between highs and lows has been found in COMT polymorphism (Szekely et al., 2010). Nonetheless, theoretically, higher dopaminergic tone could be sustained in highs by other mechanisms such as different receptors density/distribution/sensitivity, dopamine production, and catabolism by the MonoAmino-Oxidase system.

Since the very beginning of my research activity I have focused my interest on the physiological correlates of hypnotisability rather than on its psychological factors possibly accounting for hypnotic responding (Killeen and Nash, 2003; Dienes et al., 2009; Lynn and Green, 2011). In fact, I considered that the existence of a trait influencing only one aspect of behavior-the proneness to accept suggestions-would be a serious challenge to common sense, all the more that hypnotic performance was considered a consequence of peculiar attentional abilities (Raz, 2005), attention modulates several sensorimotor processes (Woollacott and Shumway-Cook, 2002; Ruff, 2013), cognitive-emotional traits have been associated with peculiar morphological characteristics of cerebellar structures (Picerni et al., 2013), and both the cerebellum and basal ganglia are often involved in nonmotor functions (Stoodley, 2012; Leisman and Melillo, 2013; Keren-Happuch et al., 2014).

My intuition was correct. Indeed, I have found hypnotizability-related differences (Carli et al., 2006, 2008; Santarcangelo et al., 2008, 2010; Menzocchi et al., 2010, 2012; Castellani et al., 2011; Scattina et al., 2012) in many aspects of sensorimotor integration in both the absence (Table 1) (Collins and De Luca, 1993; Caratelli et al., 2010; Mecacci et al., 2013) and the presence of suggestions. I have chosen the differences in postural control induced by imagined sensory alteration (Carli et al., 2006; Santarcangelo et al., 2010; Scattina et al., 2012) as the object of this article. I will also show that my physiological approach to the field of hypnotizability allows to suggest that the involuntariness reported by highs in their response to sensory suggestions is physiologically sustained and, thus, "real" rather than only subjectively experienced (Santarcangelo et al., 2010).

\section{POSTURAL EFFECTS OF IMAGINED SENSORY ALTERATION}

The experience of involuntariness in hypnotic responding has been attributed by neo-dissociative theories to dissociation between experience or executive control and behavior, and by socio-cognitive theories to deep absorption in mental images associated with high expectancy of behavior congruent with the suggestions content (Lynn and Green, 2011).

Different cortical activities have been observed during active, passive and hypnotically-induced movements (Kosslyn et al., 2001; Blakemore et al., 


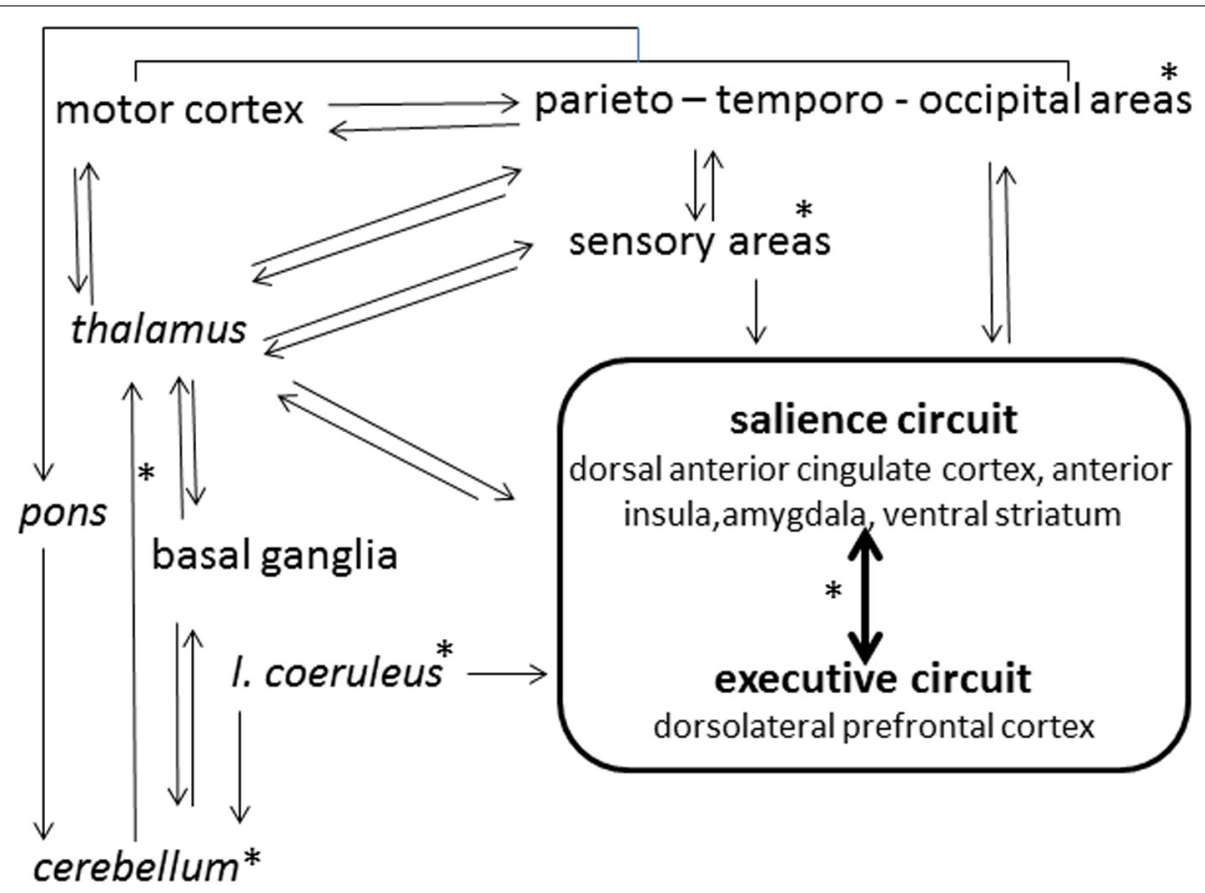

FIGURE 1 | Schematic view of hypnotizability-related differences in the brain activity. * Structures and connections (arrows) possibly involved.

Table 1 | Sensori-motor integration in not hypnotized highs not receiving any suggestion.

\section{SPINAL REFLEXES DURING LONG LASTING RELAXATION (Carli et al., 2008)}

Habituation of the soleus muscle $\mathrm{H}$ reflex

Reduction of the F wave frequency of occurrence (right hand abductor digiti minimi*)

\section{POSTURAL CONTROL*}

Greater independence of peripheral information (Santarcangelo et al., 2008)

Larger range of body sway not associated with peripherally-induced correction (Santarcangelo et al., 2008)

Postural behavior similar to lows in highly demanding postural tasks (Caratelli et al., 2010; Mecacci et al., 2013)

WALKING DIRECTION DURING BLINDFOLDED LOCOMOTION (Menzocchi et al., 2010)

Larger variability in basal conditions

Scarce influence of tonic head rotation

\section{HAPTIC EXPLORATION}

More accurate angle reproduction (Menzocchi et al., 2012)

More frequent visual recognition of meaningless objects (Castellani et al., 2011)

*Stabilogram diffusion analysis (Collins and De Luca, 1993) revealed different internal models for postural control in highs and lows during suppression of vision and alteration of the leg proprioceptive information (Santarcangelo et al., 2008). Nonetheless, highs were not less efficient than lows in maintaining balance when postural conditions were highly demanding and required higher engagement of sensory feed-back mechanisms, as occurs on see-saw platforms (Caratelli et al., 2010) and in one legged stance (Mecacci et al., 2013).

2003; Cardena et al., 2012), and the observed activation of the inferior parietal cortex has been assumed as responsible for perceived involuntariness (Blakemore et al., 2003), whereas physiological automaticity in hypnotic responding has never been demonstrated. I have approached this topic through a number of postural studies (Carli et al., 2006; Santarcangelo et al., 2010; Scattina et al., 2012).
It is well-known that imagined and physically- induced perceptions as well as imagined and real voluntary movements activate the same neural circuits, although to different extent (Jeannerod, 2001; Kosslyn et al., 2001; Moulton and Kosslyn, 2009; Munzert et al., 2009; Hétu et al., 2013). Several observations suggest a more effective activation of these circuits in highs.
In fact, only highs exhibited a backward body displacement (as expected on the basis of the inertia law) while standing and receiving the instruction to imagine that a carpet was under their feet and was being abruptly pulled forward (Carli et al., 2006). In this study, the expected behavior was not explicitly described by the suggestion script; in addition, participants reported not to have predicted 
their movement on the basis of pertaining physical laws and to have experienced their backward sway as involuntary. Thus, it appeared unlikely that their movement was triggered by absorption/expectation, as suggested by Kirsch and Lynn (1999), but we did not have any objective evidence of involuntariness.

In another study, during imagery of procedural leg pain (Scattina et al., 2012), that is while imagining that "the surgeon is taking out some pebbles from the left calf, he is using tweezers, he cannot avoid tearing away small pieces of flesh... unfortunately there is no anesthetic...," only highs exhibited a postural response (larger and faster body sway with respect to rest, displacement of the Center of Pressure (CoP) toward the site opposite to the imagined nociceptive stimulation) congruent with the suggestion administered and reported it as involuntary. Covariate analysis showed that their body displacement was not completely accounted for by the vividness of imagery, absorption in the task and perceived pain intensity; in fact, the CoP displacement toward the opposite side was independent of all these factors. Thus, again our findings challenged the hypothesis that absorption/expectation may be sufficient to account for the observed motor response. Nonetheless, participants may have been aware that pain in one leg induces a displacement toward the other leg and/or remember similar real situations, thus again we had no evidence of involuntariness.

\section{THE VESTIBULO-SPINAL REFLEX: A PROBE FOR INVOLUNTARINESS}

We designed an experiment to assess whether the perception of involuntariness may be sustained by physiological automaticity (Santarcangelo et al., 2010). In particular, we chose the vestibulo-spinal reflex (VR) evoked by galvanic stimulation of the labyrinth as a "probe for involuntariness." In fact, the vestibular stimulation induces body sway depending on the head position with respect to the body (Manzoni, 2005; Shaikh et al., 2005), that is in the frontal plane with the participant's head directed forward and in the sagittal plane with the head rotated toward one side. This shift in the direction of body sway depends on the cerebellar integration of vestibular and neck proprioceptive inputs (Kammermeier et al., 2009). In addition, the VR earliest component elicited in any head position is not modulated by expectancy (Guerraz and Day, 2005) and volition (Reynolds, 2010).

We elicited VR in highs and lows with their head directed forward as well as physically and imaginatively rotated toward one side (“...please, imagine that your head is rotated toward the right side... you can see your chin aligned with your shoulder... and feel the tension in your neck muscles...") and observed that only the highs' VR earliest component occurred in the sagittal plane for both the real and imagined head rotation, in spite of the similar absorption and vividness of imagery. Given the characteristics of VR, we have to admit that imagery of "rotated head" generated the same neural conditions associated with real head rotation, despite the subjects could not predict which neural circuits should be activated/inhibited and the studied reflex could not be voluntarily controlled. In other words, highs can transform into appropriate neural activations not only the mental images of voluntary movement and of selected perceptions (Jeannerod, 2001; Kosslyn et al., 2001; Moulton and Kosslyn, 2009; Munzert et al., 2009; Hétu et al., 2013), as observed in the general population, but also the images of sensory contexts whose neural correlates cannot be predicted and controlled.The highs' experience of involuntariness may reflect this "automatic" activation of neural circuits enabling these individuals to change their internal model for postural control according to their mental images. This change does not require any dissociative barrier (Dienes et al., 2009; Dell, 2010; Lynn and Green, 2011), is not a consequence of deep absorption/high expectancy (Lynn and Green, 2011), and cannot be assimilated to the preparation of voluntary movements (Custers and Aarts, 2010).

The highs' deeper embodiment of the image of rotated head, however, may derive also from their preferential employment of the kinesthetic modality of imagery. In fact, in line with earlier findings (Carli et al., 2007), they more often reported to have "felt the neck muscles tension" rather than to have "seen their chin in line with the shoulder"(Santarcangelo et al., 2010), and the kinesthetic modality is more efficacious than the visual one in the body representation (Shenton et al., 2004).

In contrast to the imagery of rotated head, which consists of an entirely imagined sensory context, the obstructive suggestion of anesthesia, which requires only the ability to attenuate/abolish the perception of a physical stimulation, reduces the amplitude of the VR earliest component in both groups (Santarcangelo et al., 2010), as observed for the suggestion of analgesia during nociceptive stimulation (Santarcangelo et al., 2013). Thus, on the basis of the observed hypnotizability-related capacity to transform mental images into sensori-motor physiological conditions, highs may represent the upper extreme of a continuum in the ability to modulate neural conditions through imagery.

\section{RESPONSES TO SENSORY SUGGESTIONS AND THE CEREBELLUM}

Impaired performance at cerebellar tests during suggestions of anesthesia had suggested a cerebellar involvement in the motor response to sensory suggestions, but hypnotic relaxation may have influenced the performance (Wallace and Hoyenga, 1981). It has been also shown that overactivity in the cerebellum and in the parietal cortex is associated with the misattribution of actions to an external source (Blakemore et al., 2003), but this report did not consider a possible real, physiologically based involuntariness.

In our study of the imagery of rotated head (Santarcangelo et al., 2010) the embodiment of the mental image of rotated head involuntarily produced is likely to enable the cerebellum to act routinely on the imaginatively constructed sensory information. Alternatively, imagery-triggered top down signals may change the cerebellar internal model according to the mental images' content. In both instances, the perceived involuntariness would be physiologically sustained. In contrast, in the studies on imagery of leg pain (Scattina et al., 2012) and of inertial backward falling (Carli et al., 2006), in which the response to suggestions could be expected and voluntarily controlled (despite the participants' 
subjective reports), real involuntariness could be sustained by reduced cerebellar inhibition (Groiss and Ugawa, 2013) of motor cortices (Figure 1).

Together with parietal associative areal, the cerebellum is likely to be responsible also for the different internal models (Ito, 2006) for postural control observed in highs and lows in the absence of suggestions (Santarcangelo et al., 2008). It should be also studied whether cerebellar peculiarities may contribute to the cognitive aspects of hypnotic responding through vestibulo-coeruleus and rubrothalamo-prefrontal pathways (Groiss and Ugawa, 2013).

\section{FRONTIERS: HYPNOTIZABILITY AND NITRIC OXIDE}

Studies of the post-occlusion flowmediated dilation (FMD) of the brachial artery (Green et al., 2014) have indicated greater availability of endothelial nitric oxide (NO) in highs during mental stress and nociceptive stimulation (Jambrik et al., 2005). A quite important question is whether, in these individuals, larger NO availability characterizes also the brain vessels. In fact, the brain endothelial NO is responsible for basal vascular tone, interacts with other mediators, and acts as a neurotransmitter after diffusion to the extracellular compartment. Thus, (Figure 1), in the whole brain, endothelial NO could prime cascade processes modulating the neuronal activity in highs and lows differentially. In addition, in animals NO increases the release of acetylcholine, decreases the dopamine release and increases its metabolism; in humans, larger endothelial NO availability in hypnotizability-related circuits (Hoeft et al., 2012) could account for the highs' attentional characteristics (see Presciuttini et al., 2014) and could be involved in the cognitive aspects of hypnotizability.

In the cerebellum $\mathrm{NO}$ acts also as a negative regulator of granule cell precursor proliferation, promotes survival and differentiation of these neurons and regulates bidirectional plasticity at parallel fiberPurkinje neuron synapses (Contestabile, 2012). Thus, in the cerebellum, NO could be responsible for different functional properties. On the whole, highs and lows may exhibit NO-dependent different activation of sensory and associative regions such as those belonging to the salience and executive circuits, cerebellar inhibition of the motor cortex, internal model for postural control.

In conclusion, our findings allow to include hypnotizability among the individual traits responsible for part of the variability in postural control and indicate that it may be involved in the construction of individual sensorimotor selves. They suggest a key role of the cerebellum in hypnotic responding and go beyond psychological theories by suggesting that the involuntariness in action reported after a few sensori-motor suggestions can be real rather than merely experienced.

\section{ACKNOWLEDGMENTS}

I am sincerely grateful to D. Manzoni for his advice on vestibulo-cerebellar physiology and to E. Scattina for her enthusiastic collaboration. The discussed research was funded by the Italian Space Agency (ASI).

\section{REFERENCES}

Blakemore, S. J., Oakley, D. A., and Frith, C. D. (2003). Delusions of alien control in the normal brain. Neuropsychologia 41, 1058-1067. doi: 10.1016/S0028-3932(02)00313-5

Caratelli, E., Menzocchi,M., Carli,G., Fontani, G., and Santarcangelo, E. L. (2010). Is high hypnotizability a trouble in balance control? Eur. J. Appl. Physiol. 108, 201-206. doi: 10.1007/s00421-009-1280-6

Cardena, E., Lehmann, D., Faber, P. L., Jonsson, P., Milz, P., Pasqual-Marqui, R. D., et al. (2012). EEGs Loreta functional imaging during hypnotic arm levitation and voluntary arm lifting. Int. J. Clin. Exp. Hypn. 60, 31-53. doi: 10.1080/00207144.2011.622184

Carli, G., Cavallaro, F. I., Rendo, C. A., and Santarcangelo, E. L. (2007). Imagery of different sensory modalities: hypnotizability and body sway. Exp. Brain Res. 179, 47-54. doi: 10.1007/s00221006-0776-0

Carli, G., Manzoni, D., and Santarcangelo, E. L. (2008). Hypnotizability-related integration of perception and action. Cogn. Neuropsychol. 25, 1065-1076. doi: 10.1080/02643290801913712

Carli, G., Rendo, C., Sebastiani, L., and Santarcangelo, E. L. (2006). Suggestions of altered balance: possible equivalence of imagery and perception. Int. J. Clin. Exp. Hypn. 54, 206-223. doi: 10.1080/00207140500528455

Castellani, E., Carli, G., and Santarcangelo, E. L. (2011). Visual identification of haptically explored objects in high and low hypnotizable subjects. Int. J. Clin. Exp. Hypn. 59, 250-265. doi: 10.1080/00207144.2011.546269

Castellani, E., D'Alessandro, L., and Sebastiani, L. (2007). Hypnotizability and spatial attentional functions. Arch. Ital. Biol. 145:23-37.

Collins, J. J., and De Luca, C. J. (1993). Open-loop and closed-loop control of posture: a randomwalk analysis of center-of-pressure trajectories.
Exp. Brain Res. 95, 308-318. doi: 10.1007/BF00 229788

Contestabile, A. (2012). Role of nitric oxide in cerebellar development and function:focus on granule neurons. Cerebellum 11, 50-61. doi: 10.1007/s12311-010-0234-1

Custers, R., and Aarts, H. (2010). The unconscious will: how the pursuit of goals operates ouside of conscious awareness. Science 329, 47-50. doi: 10.1126/science. 1188595

Dell, P. F. (2010). Involuntariness in hypnotic responding and dissociative symtoms. J. Trauma Dissoc. 1, 1-18. doi: 10.1080/15299730903 317964

Dienes, Z., Brown, E., Hutton, S., Kirsch, I., Mazzoni, G., and Wright, D. B. (2009). Hypnotic suggestibility, cognitive inhibition, and dissociation. Conscious. Cogn. 18, 837-847. doi: 10.1016/j.concog.2009.07.009

Egner, T., Jamieson, G. A., and Gruzelier, J. (2005). Hypnosis decouples cognitive control from conflict monitoring processes of the frontal lobe. Neuroimage 7, 2969-2978. doi: 10.1016/j.neuroimage.2005.05.002

Green, D. J., Dawson, E. A., Groenewoud, H. M., Jones, H., and Thijssen, D. H. (2014). Is flow-mediated dilation nitric oxide mediated?:A meta-analysis. Hypertension 63, 376-382. doi: 10.1161/HYPERTENSIONAHA.113.02044

Green, J. P., Barabasz, A. F., Barrett, D., and Montgomery, G. H. (2005). Forging ahead: the 2003 APA Division 30 definition of hypnosis. Int. J. Clin. Exp. Hypn. 53, 259-264. doi: 10.1080/00207140590961321

Groiss, S. J., and Ugawa, Y. (2013). Cerebellum. Handb. Clin. Neurol. 116, 643-653. doi: 10.1016/B978-0-444-53497-2.00051-6

Guerraz, M., and Day, B. L. (2005). Expectation and the vestibular control of balance. J. Cogn. Neurosci. 17, 463-469. doi: 10.1162/0898929053279540

Hétu, S., Grégoire, M., Saimpont, A., Coll, M. P., Eugène, F., Michon, P. E., et al. (2013). The neural network of motor imagery: an ALE metaanalysis. Neurosci. Biobehav. Rev. 37, 930-949. doi: 10.1016/j.neubiorev.2013.03.017

Hoeft, F., Gabrieli, J. D., Whitfield-Gabrieli, S., Haas, B. W., Bammer, R., Menon, V., et al. (2012) Functional brain basis of hypnotizability. Arch. Gen. Psychiatry 69, 1064-1072. doi: 10.1001/archgenpsychiatry.2011.2190

Ito, M. (2006). Cerebellar circuitry as a neuronal machine. Prog. Neurobiol. 7, 272-303. doi: 10.1016/j.pneurobio.2006.02.006

Jambrik, Z., Carli, G., Rudish, T.,Varga, A., Forster, T., and Santarcangelo, E. L. (2005). Modulation of pain-induced endothelial dysfunction by hypnotisability. Pain 116, 81-86. doi: 10.1016/j.pain.2005.03.041

Jamieson, G. A., and Sheehan, P. W. (2004). An empirical test of Woody and Bowers's dissociated control theory of hypnosis. Int. J. Clin. Exp. Hypn. 52, 232-249. doi: 10.1080/00207140490 52349

Jeannerod, M. (2001). Neural simulation of action: a unifying mechanism for motor cognition. Neuroimage 4, S103-S109. doi: 10.1006/nimg. 2001.0832

Kammermeier, S., Kleine, J., and Büttner, U. (2009). Vestibular-neck interaction in cerebellar 
patients. Ann. N.Y. Acad. Sci. 1164, 94-99. doi: 10.1111/j.1749-6632.2009.03861.x

Keren-Happuch, E., Chen, S. H., Ho, M. H., and Desmond, J. E. (2014). A meta-analysis of cerebellar contributions to higher cognition from PET and fMRI studies. Hum. Brain Mapp. 35, 593-615. doi: 10.1002/hbm.22194

Kihlstrom, J. F., Register, P. A., Hoyt, I. P., Albright, J. S., Grigorian, E. M., Heindel,W. C., et al. (1989). Dispositional correlates of hypnosis: a phenomenological approach. Int. J. Clin. Exp. Hypn. 37, 249-263. doi: 10.1080/0020714890 8414476

Killeen, P. R., and Nash, R. (2003). The four causes of hypnosis. Int. J. Clin. Exp. Hypn. 51, 195-231. doi: 10.1076/iceh.51.3.195.15522

Kirsch, I., and Lynn, J. (1999). Automaticity in clinical psychology. Am. Psychol. 4, 504-515. doi: 10.1037/0003-066X.54.7.504

Kosslyn, M., Ganis, G., and Thompson,W. L. (2001). Neural foundations of imagery. Nat. Rev. Neurosci. 2, 635-642. doi: 10.1038/35090055

Leisman, G., and Melillo, R. (2013). The basal ganglia: motor and cognitive relationships in a clinical neurobehavioral context. Rev. Neurosci. 24, 9-25. doi: 10.1515/revneuro-2012-0067

Lynn, S. J., and Green, J. P. (2011). He sociocognitive and dissociation theories of hypnosis: toward a rapprochement. Int. J. Clin. Exp. Hypn. 59, 277-293. doi: 10.1080/00207144.2011.570652

Madeo, M., Castellani, E., Santarcangelo, E. L., and Mocenni, C. (2013). Hypnotic assessment based on the recurrence quantification analysis of EEG recorded in the ordinary state of consciousness. Brain Cogn. 83, 27-233. doi: 10.1016/j.bandc.2013.08.002

Manzoni, D. (2005). The cerebellum may implement the appropriate coupling of sensory inputs and motor responses: evidence from vestibular physiology. Cerebellum 4, 78-88. doi: 10.1080/14734220500193493

Mecacci, G., Menzocchi, M., Zeppi, A., Carli, G., and Santarcangelo, E. L. (2013). Body sway modulation by hypnotisability and gender during low and high demanding postural conditions. Arch. Ital. Biol. 151, 99-105. doi: 10.4449/aib.v151i3.1489

Menzocchi, M., Paoletti, G., Huber, A., Carli, G., Cavallaro, F. I., Manzoni, D., et al. (2010). Hypnotizability and sensorimotor integration: an italian space agency project. Int. J. Clin. Exp. Hypn. 58, 122-135. doi: 10.1080/00207140903316169

Menzocchi, M., Santarcangelo, E. L., Carli, G., and Berthoz, A. (2012). Hypnotizability-dependent accuracy in the reproduction of haptically explored paths. Exp. Brain Res. 216, 217-223. doi: 10.1007/s00221-011-2922-6

Meyer, E. C., and Lynn, S. J. (2011). Responding to hypnotic and non-hypnotic suggestions: performance standards, imaginative suggestibility, and response expectancies. Int. J. Clin. Exp. Hypn. 59, 327-349. doi: 10.1080/00207144.2011.570660

Moulton, S. T., and Kosslyn, M. (2009). Imagining predictions: mental imagery as mental emulation. Philos. Trans. R. Soc. Lond. B Biol. Sci. 364, 1273-1280. doi: 10.1098/rstb.2008.0314

Munzert, J., Lorey, B., and Zentgraf, K. (2009). Cognitive motor processes: the role of motor imagery in the study of motor representations. Brain Res. Rev. 60, 306-326. doi: 10.1016/j.brainresrev.2008.12.024

Picerni, E., Petrosini, L., Piras, F., Laricchiuta, D. Cutuli, D., Chiapponi, C., et al. (2013). New evidence for the cerebellar involvement in personality traits. Front. Behav. Neurosci. 7:133. doi: 10.3389/ fnbeh.2013.00133

Presciuttini, S., Gialluisi, A., Barbuti, S., Curcio,M., Scatena,F., Carli, G., et al. (2014). Hypnotizability and Catechol-O-Methyltransferase (COMT) polymorphysms in Italians. Front. Hum. Neurosci. 7:929. doi: 10.3389/fnhum.2013.00929

Raz, A. (2005). Attention and hypnosis: neural substrates and genetic associations of two converging processes. Int. J. Clin. Exp. Hypn. 53, 237-258. doi: 10.1080/00207140590961295

Reynolds, R. (2010). The effects of voluntary sway control on the early and late components of the vestibular-evoked postural responses. Exp. Brain Res. 201, 33-39. doi: 10.1007/s00221-0092017-9

Ruff, C. C. (2013). Sensory processing: who's in (topdown) control? Ann. N.Y. Acad. Sci. 1296, 88-107. doi: $10.1111 /$ nyas. 12204

Santarcangelo, E. L., Paoletti, G., Chiavacci, I., Palombo, C., Carli, G., and Varanini, M. (2013). Cognitive modulation of psychophysical, respiratory and autonomic responses to cold pressor test. PLoS ONE 8:e75023. doi: 10.1371/journal.pone. 0075023

Santarcangelo, E. L., Scattina, E., Carli, G. Ghelarducci, B., Orsini, P., and Manzoni, D. (2010). Can imagery become reality? Exp. Brain Res. 206, 29-335. doi: 10.1007/s00221-010-2412-2

Santarcangelo, E. L., Scattina, E., Carli, G., Macerata, A., and Manzoni, D. (2008). Hypnotizabilitydependent modulation of postural control: effects of alteration of the visual and leg proprioceptive inputs. Exp. Brain Res. 191, 331-340. doi: 10.1007/s00221-008-1526-2

Scattina, E., Huber, A., Menzocchi, M., Paoletti, G., Carli, G., Manzoni, D., et al. (2012). Postural effects of imagined leg pain as a function of hypnotizability. Exp. Brain Res. 216, 341-348. doi: 10.1007/s00221-011-2935-1

Shaikh, A. G., Ghasia, F. F., Dickman, J. D., and Angelaki, D. E. (2005). Properties of cerebellar fastigial neurons during translation, rotation, and eye movements. J. Neurophysiol. 93, 853-863. doi: 10.1152/jn.00879.2004
Sheehan, P., and McConkey, K. (1982). Hypnosis and Experience: the Exploration of Phenomena and Processes. Hillsdale, NJ: Erlsbaum.

Shenton, J. T., Schwoebel, J., and Coslett, H. B. (2004). Mental motor imagery and the body schema: evidence for proprioceptive dominance. Neurosci. Lett. 370, 19-24. doi: 10.1016/j.neulet.2004. 07.053

Stoodley, C. J. (2012). The cerebellum and cognition: evidence from functional imaging studies. Cerebellum 11, 352-365. doi: 10.1007/s12311-0110260-7

Szekely, A., Kovacs-Nagy, R., Bányai, E. I., GosiGreguss, A. C., Varga, K., Halmai, Z., et al. (2010). Association between hypnotizability and the catechol-O-methyltransferase (COMT) polymorphism. Int. J. Clin. Exp. Hypn. 58, 301-315. doi: 10.1080/00207141003760827

Tellegen, A., and Atkinson, G. (1974). Openness to absorbing and self-altering experiences ("absorption"), a trait related to hypnotic susceptibility. J Abnorm. Psychol. 83, 268-277. doi: 10.1037/h0036681

Varga, K., Németh, Z., and Szekely, A. (2011). Lack of correlation between hypnotic susceptibility and various components of attention. Conscious. Cogn. 20, 1872-1881. doi: 10.1016/j.concog.2011. 09.008

Wallace, B., and Hoyenga, K. B. (1981). Performance of fine motor coordination activities with an hypnotically anesthetized limb. Int. J. Clin. Exp. Hypn. 29, 54-65. doi: 10.1080/00207148108409143

Woollacott, M., and Shumway-Cook, A. (2002). Attention and the control of posture and gait: a review of an emerging area of research. Gait Posture 16, 1-14. doi: 10.1016/S09666362(01)00156-4

Conflict of Interest Statement: The author declares that the research was conducted in the absence of any commercial or financial relationships that could be construed as a potential conflict of interest.

Received: 25 April 2014; accepted: 04 June 2014; published online: 24 June 2014.

Citation: Santarcangelo EL (2014) New views of hypnotizability. Front. Behav. Neurosci. 8:224. doi: 10.3389/ fnbeh.2014.00224

This article was submitted to the journal Frontiers in Behavioral Neuroscience.

Copyright (c) 2014 Santarcangelo. This is an openaccess article distributed under the terms of the Creative Commons Attribution License (CC BY). The use, distribution or reproduction in other forums is permitted, provided the original author(s) or licensor are credited and that the original publication in this journal is cited, in accordance with accepted academic practice. No use, distribution or reproduction is permitted which does not comply with these terms. 